\title{
Patient satisfaction at the Medical Emergency department at Holbæk Hospital
}

\author{
Samia Ditta \\ From Danish Society for Emergency Medicine: Research Symposium 2010 \\ Roskilde, Denmark. 20-21 May 2010
}

\section{Background}

The purpose of the study was to examine patient satisfaction at the Medical Emergency department at Holbæk Hospital, and to investigate patient satisfaction for subject groups such as nurses and doctors in medical reception and waiting in reception.

\section{Methods}

The group of persons to be included in the study were patients in medical reception and they were all medical patients, apart from patients who were very acute influenced and therefore could not participate. Patients received a questionnaire. In the questionnaire the patient considered the waiting time in medical reception and the nurses and doctors treatment of the individual patient. The patient could express himself through two options, by indicating satisfactory or unsatisfactory. After the patients had answered and returned the questionnaire, they were grouped together and the responses got analyzed in percentage.

\section{Results}

A total of 20 patients replied. 5\% of patients were not satisfied with waiting time in reception and $95 \%$ were satisfied. $10 \%$ of the patients were not satisfied with the waiting time before the first doctor visit and $90 \%$ were satisfied. $100 \%$ of patients were satisfied with waiting time before the patient comes to section. $5 \%$ of the patients were not satisfied regarding nursing and 95\% were satisfied. Regarding communication between patient and nurse $10 \%$ patient were not satisfied and $90 \%$ were satisfied. $10 \%$ were not satisfied about information and $90 \%$ were satisfied. $100 \%$ were satisfied regarding patient satisfaction medical treatment. 5\% were not satisfied with communication between patient

Correspondence: ditta@mail.com

Emergency Department, Holbæk Hospital, Denmark and doctor and $95 \%$ was satisfied. $5 \%$ were not satisfied with the further information and 95\% were satisfied.

\section{Conclusion}

The results show that the majority of patients are satisfied with waiting in the reception where only $5 \%$ are dissatisfied. $10 \%$ of the respondents are dissatisfied with waiting times within the first doctor visit. $5 \%$ are dissatisfied by the nursing and $10 \%$ are dissatisfied by the communication between patient and nurse. $10 \%$ are dissatisfied about information on their health progress. In addition, $5 \%$ are unsatisfied with the communication between doctor and patient and the information received on how to proceed in treatment. There must however be subject to bias in this study, since almost all questionnaires were given by the same doctor who treated the patients. Another factor is that the survey was conducted in a small number with only 20 returned questionnaires. This is not a representative amount of respondents.

Published: 17 September 2010

doi:10.1186/1757-7241-18-S1-P24

Cite this article as: Ditta: Patient satisfaction at the Medical Emergency department at Holbæk Hospital. Scandinavian Journal of Trauma, Resuscitation and Emergency Medicine 2010 18(Suppl 1):P24. 